medical experts-"community health advisers." Many of the current functions of specialists in community medicine could be undertaken by these advisers, says the report-solving at a stroke the problems now attributed to shortage of staff and saving money on both salaries and training.

Clearly a brief report (126 pages) can only outline the USHP proposals, but they warrant serious attention by community physicians. Radical changes are needed to deal with the low morale in the specialty and poor recruitment. The concentration on administration and committee work that has characterised the infancy of the specialty seems likely to be seen, with hindsight, as mistaken. It is by no means too late for a change in direction.

${ }^{1}$ Unit for the Study of Health Policy, Rethinking Community Medicine: Towards a Renaissance in Public Health? USHP, 8 Newcomen Street, London SE1 1YR (price $£ 2 \cdot 50$ ), 1979.

\section{Infective endocarditis with negative blood cultures}

Though infective endocarditis.can now be cured, the death rate is still $30 \%{ }^{12}$ Patients die not of uncontrolled infection but of the late mechanical effects of their destructive lesions, often causing gross heart failure. ${ }^{3} \mathrm{~A}$ major factor in this story is delay in presentation, in diagnosis, and in starting treatment once the diagnosis is suspected rather than waiting for bacteriological proof. One group of patients which fares particularly badly are those with endocarditis but persistently negative blood cultures. While criteria for its diagnosis vary, this group forms an average of $20 \%$ of most published series. Attempts to reduce this proportion have been only partially successful even in the best centres using modern laboratory techniques.

Endocarditis, which is usually caused by streptococci, may also be caused by a group of fastidious Gram-negative rods that are rarely pathogenic in man. They are Haemophilus aphrophilus ( $H$ influenzae rarely causes endocarditis), ${ }^{4}$ Actinobacillus actinomycetemcomitans, ${ }^{5}$ Cardiobacterium hominis, ${ }^{6} 7$ and Streptobacillus moniliformis. ${ }^{7}$ They are all rare causes, accounting for only a tiny proportion of the "difficult" cases. We now know that Staphylococcus epidermidis and diphtheroid bacilli, commonly associated with postoperative endocarditis, may cause non-operative endocarditis, usually in older people. Coxiella burneti, ${ }^{9}$ Chlamydia psittaci $^{10}$ and $C$ trachomatis ${ }^{11}$ have been recognised as non-bacterial causes of endocarditis, and account for some of the cases with negative blood cultures. It is important to recognise this possibility, as the treatment for organisms which lack a rigid cell wall is radically different: penicillins are ineffective and long-term tetracyclines are required. A viral aetiology for culture-negative endocarditis has been postulated but there is no good evidence for this, in spite of the Coxsackie group being commonly associated with myocarditis and pericarditis. If viral endocarditis does occur it is exceedingly rare.

Many physicians still seem uncertain about the best approach to treatment for patients who are culture-negative. Some at least are known to respond to the combination of benzylpenicillin and an aminoglycoside. These should be used as initial treatment for all cases of non-operative endocarditis whether culture-negative or culture-positive. Metabolically aberrant, thiol-dependent streptococci (satelliting streptococci $)^{12}$ respond to the combination but not usually to penicillin alone. These organisms, which require a source of sulphydryl groups, often grow well in the blood culture bottle but slowly, if at all, on routine solid media. What about patients who have been given antibiotics before admission-often without a diagnosis of endocarditis having been made? Many such patients have negative blood cultures when they present, ${ }^{13} 14$ even though the treatment given has usually been inappropriate and will always have been incomplete. How many cases of endocarditis are actually rendered culture-negative is not clear. One case has been reported where unintentional administration of a single dose of penicillin rendered cultures negative for 17 days. ${ }^{15}$ Again, however, the best treatment option is a combination of benzylpenicillin and an aminoglycoside.

A recent publication from Iowa ${ }^{16}$ clarifies the problem of culture-negative cases in general, and the effect of prior antibiotic administration in particular. It is a retrospective study of a heterogeneous series of 52 culture-negative cases. Twentyone occurred over the same period as 84 culture-positive cases, giving the expected $20 \%$ ratio. The culture-negative cases were indistinguishable on presentation from those with positive cultures. Some responded rapidly to treatment, but the response and survival of culture-negative cases were similar to those cases with the worst prognosis: those caused by Staph aureus, and infections affecting prosthetic valves. Thirty of the 52 culture-negative cases survived, two-thirds of them responding rapidly to treatment. Valvular tissue was examined from 19 of the 22 patients who died and from six who underwent valve surgery. In four no evidence of endocarditis was seen. In 15 organisms were seen, and in nine of these were grown. Most were Gram-positive cocci, but other bacteria appeared to have been present. Some may have represented postmortem contamination but most clearly did not. The report includes three atypical cases in which blind treatment was delayed for two weeks or more because of uncertainty about the diagnosis. All had received antibiotics previously and all yielded streptococci from cultures taken after this considerable waiting period. The study suggests that culturenegative cases are usually caused by common bacteria, rendered inaccessible by the age of the lesion or the prior use of antibiotics, rather than unusual bacteria such as brucella or bacteroides.

Definitive treatment of non-operative cases of bacterial endocarditis with benzylpenicillin and gentamicin should be started at once without awaiting results. Long delays in the hope of obtaining a positive culture will rarely prove fruitful, and may be catastrophic. Treatment with antibiotics should be continued for six weeks, as in culture-positive cases, and should be stopped only in those rare cases where a definite alternative diagnosis is forthcoming.

1 Hayward, G W, British Medical fournal, 1973, 2, 706.
2 Hayward, G W, British Medical fournal, 1973, 2, 764.
3 Wise, J R, et al, Lancet, 1971, 2, 115.
4 Geraci, J E, et al, Mayo Clinic Proceedings, 1977, 52, 209.
5 Vandepitte, J, Geest, H de, and Jousten, P, fournal of Clinical Pathology,
1977, 30, 842.
Jobanputra, R S, and Moysey, J, fournal of Clinical Pathology, 1977, 30,
1033.
7idgley, J, et al, fournal of Medical Microbiology, 1970, 3,91.
8 Andrews, P S, and Marmion, B P, British Medical fournal, 1959, 2, 983.
Robson, A O, and Shimmin, C D E L, British Medical fournal, 1959, 2,
980.
10 Levison, D A, et al, Lancet, 1971, 2, 844.
11 van der Bel-Kahn, J M, et al, American Heart fournal, 1978, 95, 627.
12 McCarthy, L R, and Bottone, E J, American fournal of Clinical Pathology,

12 McCarthy, L R, and Bottone, E J, American fournal of Clinical Pathology, $1974,61,585$.

13 Smith, R H, et al, Thorax, 1976, 31, 373.

14 Werner, A S, et al, fournal of the American Medical Association, 1967, 202, 199.

15 Balme, H W, and Dormer, A E, British Medical fournal, 1954, 1, 500.

16 Pesanti, E L, and Smith, I M, American fournal of Medicine, 1979, 66, 43. 